\title{
Análise lexicográfica de dicionários de comunicação
}

\author{
Analysis of lexicographical dictionaries of communication \\ Jéssica Câmara Siqueira ${ }^{I}$ \\ (jessica.siqueira@usp.br) \\ http://dx.doi.org/10.5216/cei.v16i2.26948
}

\begin{abstract}
Resumo
A área da Comunicação, por sua constituição recente, possui poucos materiais lexicográficos e muitos apresentam problemas de falta de sistematização e padronização. A partir do aporte teórico e metodológico da Lexicografia são analisados quatro dicionários da área da Comunicação, sendo dois de cobertura mais abrangente e dois de caráter mais técnico, referentes a duas subáreas. O objetivo é analisar a macro e a microestrutura desses dicionários, apontando os aspectos positivos e negativos quanto às escolhas terminológicas e a estrutura organizacional das obras lexicográficas. A análise desses aspectos resulta na concepção de um roteiro para auxiliar a elaboração de dicionários nessa área de especialidade.
\end{abstract}

Palavras-chave: Comunicação. Dicionários. Lexicografia.

\begin{abstract}
The Social Communication has few lexicographical materials and many have problems with lack of systematization and standardization. From the theoretical and methodological Lexicography four dictionaries are analyzed, two dictionaries to more comprehensive coverage and two other more technical. The aim is to analyze the macro and microstructure of these dictionaries, pointing out the positive and negative aspects regarding the choices terminology and organizational structure them. The analysis of these aspects results in designing a roadmap to assist the preparation of dictionaries in this specialty area.
\end{abstract}

Keywords: Communication. Dictionary. Lexicography.

\section{Introdução}

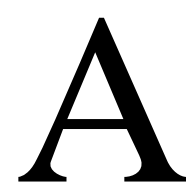

Coordenação de Aperfeiçoamento de Pessoal de Nível Superior (Capes) classifica as áreas do conhecimento segundo uma finalidade eminentemente prática, voltada à sistematização das informações em seu contexto de uso dentro de um domínio, bem

\footnotetext{
${ }^{1}$ Doutorado em andamento em Letras na Faculdade de Filosofia Letras e Ciências Humanas da Universidade de São Paulo. Mestre em Ciência da Informação pela Escola de Comunicações e Artes da Universidade de São Paulo. Especialização em Arquivos pelo Instituto de Estudos Brasileiro da Universidade de São Paulo (2009).Graduação em Biblioteconomia pela Universidade de São Paulo (2009).Graduação em Letras pela Universidade de Marília(2002).
}

Comum \& Inf, v. 16, n. 2, p. 05-22, jul./dez. 2013 
como permite o olhar das possíveis interfaces entre as áreas. Para isso, a Capes, em parceria com outras agências financiadoras - o Conselho Nacional de Desenvolvimento Científico e Tecnológico (CNPq), a Fundação de Amparo à Pesquisa do Estado do Rio Grande do Sul (FAPERGS), a Financiadora de Estudos e Projetos (Finep), a Secretaria Especial de Desenvolvimento Industrial do Ministério do Desenvolvimento Industrial (SDI/MD), a Secretaria de Ensino Superior do Ministério da Educação (Sesu/MEC) e a Secretaria de Indústria e Comércio, Ciência e Tecnologia do Estado de São Paulo - apresentou uma hierarquização em quatro níveis das áreas do conhecimento:

$1^{\circ}$ nível - Grande Área: aglomeração de diversas áreas do conhecimento em virtude da afinidade de seus objetos, métodos cognitivos e recursos instrumentais refletindo contextos sociopolíticos específicos.

$2^{\circ}$ nível - Área: conjunto de conhecimentos inter-relacionados, coletivamente construído, reunido segundo a natureza do objeto de investigação com finalidades de ensino, pesquisa e aplicações práticas.

$3^{\circ}$ nível - Subárea: segmentação da área do conhecimento estabelecida em função do objeto de estudo e de procedimentos metodológicos reconhecidos e amplamente utilizados.

$4^{\circ}$ nível - Especialidade: caracterização temática da atividade de pesquisa e ensino. Uma mesma especialidade pode ser enquadrada em diferentes grandes áreas, áreas e subáreas (CAPES, 2008, p. 1).

Dos quatro níveis apresentados somam-se um total de 08 grandes áreas, 76 áreas e 340 subáreas do conhecimento, sem contar a grande área multidisciplinar. As Ciências Sociais Aplicadas, segundo a Capes (2008), inscreve-se como uma grande área, voltada a responder às necessidades concretas da sociedade. Dentro dessa grande área destacamos a área da Comunicação. Como parte integrante da grande área de aplicação social, a Comunicação deve aliar teoria e prática como instâncias interdependentes. Além disso, seu objeto de estudo é resultado da análise dos fenômenos sociais, bem como da produção e compartilhamento de sentido entre os sujeitos.

A construção conceitual nesta área se dá na inter-relação entre o conhecimento empírico e o teórico. Todavia, a interface dessas duas perspectivas nem sempre se realiza facilmente, principalmente considerando o cenário das assimetrias trazidas junto à pós-modernidade.

Desde o século passado vimos a produção do conhecimento científico se distanciar da perspectiva positivista, mais focada na abordagem empirista e de análise objetiva, e ganhar mais espaço a perspectiva social das Ciências Humanas e Sociais Aplicadas, voltadas à análise dos fenômenos sociais e das interações entre os sujeitos.

No mundo contemporâneo, sujeito e objeto se confundem, tempo e espaço se redimensionam e as relações sociais se transformam. Os domínios que lidam com os dispositivos

Comum \& Inf, v. 16, n. 2, p. 05-22, jul./dez. 2013 
informacionais e comunicacionais não só se transformam rapidamente nesse contexto, como são influenciados pela mudança do paradigma científico. Neste novo cenário, a ciência teve que adotar novas abordagens tanto para sobreviver nesse novo contexto de complexidades, como para solucionar as exigências sociais, tecnológicas e culturais do homem contemporâneo (KLEIN, 2004).

Com tais considerações em mente, a noção de Comunicação aqui é entendida como o campo de estudos que lida com os processos comunicativos que se desenvolvem na sociedade, tanto no âmbito das organizações sociais como na inter-relação social (MARCONDES, 2009). Como área reúne como principais subáreas: a Teoria da Comunicação, Jornalismo e Editoração, Rádio, Televisão, Relações Públicas e Propaganda, Comunicação e Programação Visual (CAPES, 2008). A diversidade de subáreas revela o caráter pluridiverso da área da Comunicação, bem como indica a dificuldade de se delimitar suas fronteiras e interfaces, uma vez que também atravessa outras áreas e subáreas (KATZ, DORIA, LIMA, 1975).

Considerando as assimetrias do contexto pós-moderno verificamos que a área da Comunicação, principalmente pela questão conjuntural, apresenta escassez de materiais de teor lexicográfico, assim como análises sobre a estrutura e a construção conceitual de seus termos. Diante disso, objetiva-se analisar quatro dicionários da área, apontando os aspectos positivos e negativos quanto às escolhas terminológicas e a estrutura organizacional dessas obras lexicográficas. Dos dicionários escolhidos para a análise elegemos dois de cobertura mais abrangente, tanto pela quantidade de verbetes como pela cobertura temática dos termos; e dois dicionários de cunho mais técnico e especializado, focados em duas subáreas. Mesmo com nível de cobertura distintos, os dicionários destacam-se como relevantes materiais de referência dentro de seu domínio.

A análise é realizada a partir do aporte teórico e metodológico da Lexicografia, com ênfase nos aspectos estruturais da macro e microestrutura dos verbetes, com intuito de destacar pontos fortes e fracos nas escolhas terminológicas e organizacionais. Por fim, apresenta-se um roteiro que pode ser utilizado para posteriores elaborações de dicionários na área da Comunicação.

Um trabalho dessa natureza justifica-se principalmente por duas razões: primeiro pela carência de estudos lexicográficos na área da Comunicação, e segundo pelo recorrente problema de falta de sistematização e padronização nos dicionários dessa área. Quanto à carência de estudos, podemos justificá-la primeiramente em decorrência de a área constituir-se de subáreas delimitadas recentemente, e por isso ocorrer um grande índice de migrações conceituais, a exemplo das subáreas do Marketing, Editoração e as Relações Públicas. Outro aspecto que corrobora a carência

Comum \& Inf, v. 16, n. 2, p. 05-22, jul./dez. 2013 
de estudos é a própria escassez de dicionários na área, sendo mais recorrente o uso de glossários, obras lexicográficas de cunho mais sintético, superficial e de uso pontual.

Já o problema da sistematização não é privilégio da Comunicação, pois é comum encontrar, mesmo em dicionários de língua bem conceituados, imprecisões na seleção de corpus ou mesmo falta de homogeneidade no estabelecimento de critérios na organização e classificação das palavras.

A suposta restrição do corpus de análise justifica-se pela tentativa de realizar uma análise mais detalhada dos dicionários da área em língua portuguesa, idioma de análise. Por isso, desconsideram-se as obras lexicográficas produzidas internacionalmente na área, uma vez que vem incutidas de nuanças conceituais, culturais e conjunturais que mudariam nossa perspectiva de análise lexicográfica. Além disso, a restrição de espaço desta publicação não permitiria esse tipo de análise em uma extensão muito maior de obras.

$\mathrm{O}$ artigo divide-se em três partes: primeiro apresentaremos o aporte teórico embasado nos princípios lexicográficos utilizados para a análise de dicionários, depois analisamos os quatro dicionários de Comunicação sob o viés da Lexicografia e por fim propomos um roteiro para auxiliar a elaboração de dicionários na área.

\section{Aporte teórico}

No estudo do léxico destacam-se principalmente duas ciências, a Lexicologia e a Lexicografia. Segundo Biderman (2001) a primeira tem como objeto de estudo a palavra, preocupando-se com a estruturação do léxico e sua categorização, ocupando-se assim também da dimensão significativa, o que aproxima a Lexicologia da Semântica. Já a Lexicografia com raízes na Antiguidade só conseguiu efetivo status científico e autonomia no século XX, constituindo-se como a "ciência dos dicionários".

No século XX houve um acelerado desenvolvimento da produção de obras lexicográficas. No Brasil, mesmo com os primeiros dicionários em língua portuguesa datados do século XVIII, com destaque para as obras de Bluteau e Moraes e Silva, percebeu-se que os estudos lexicais só ganharam efetivamente um status científico após a segunda metade do século XX, principalmente a partir dos trabalhos de Biderman (1984).

Desde então, a Lexicografia ganhou cada vez mais espaço, tanto para os linguistas, que a redescobririam a partir do viés científico, como para outras áreas, que utilizaram a teoria lexical e seus critérios científicos para melhor consolidarem seus domínios. Podemos observar, portanto, que

Comum \& Inf, v. 16, n. 2, p. 05-22, jul./dez. 2013 
as obras lexicográficas acompanharam o desenvolvimento humano tanto num nível técnicocientífico como sociocultural. Todavia, sua heterogeneidade de objetivos, funções e públicos-alvo dificultaram a formulação de uma definição satisfatória de seu escopo.

Considerando tais assimetrias, optou-se em seguir a perspectiva sugerida por Campos Souto e Pérez Pascual (2003) que prefere apontar as características essenciais da obra lexicográfica, ao invés de sintetizá-la superficialmente com uma definição. A partir disso ressaltam-se duas principais propriedades, consideradas como consensuais para a maioria dos autores: a orientação prática, voltada à consulta; e a finalidade didática.

Para que ambas as propriedades funcionem de modo satisfatório devem considerar os seguintes aspetos: os diferentes objetivos do dicionário, as necessidades dos usuários, o formato e o suporte da obra lexicográfica (AHUMADA LARA, 1989). Dessa forma, um dos objetivos do dicionário seria funcionar como um instrumento cultural, detentor de um projeto didático. Além disso, ainda poderia ser encarado como um conjunto documental sistematizado, ou ainda um produto técnico-comercial.

Outro aspecto a ser lembrado é destacar as diferenças do dicionário com outras obras lexicográficas. Tanto glossários como vocabulários, muitas vezes são colocados como sinônimos de dicionários, porém, são obras lexicográficas distintas, com funções e propriedades singulares. O glossário, por exemplo, tem a função de explicar um termo em um texto ou obra, sendo, portanto, de caráter mais restritivo. O vocabulário por sua vez, mais amplo que o glossário, todavia menos abrangente que o dicionário, seria uma obra intermediária, um catálogo de acepções de palavras pertencentes a um determinado campo semântico (ISQUIERDO; ALVES, 2007).

Estruturalmente, os dicionários podem ser organizados em três grandes correntes. A primeira tem como principal autor Rey-Debove (1971) que divide a organização do dicionário em duas partes, a macroestrutura, que corresponde às entradas ou verbetes, e a microestrutura, que traz as definições dos verbetes. Seguindo essa linha, mas com uma perspectiva um pouco mais ampla, há uma segunda corrente, representada por Günther Haensch (1982 apud ISQUIERDO; ALVES, 2007). O autor retoma as noções de macro e uma microestrutura, incorporando à primeira as partes que antecedem as entradas, tais como o prólogo, introdução e prefácio, também designada como parte pré-textual. A importância dessa parte justifica-se por apresentar os critérios de seleção e

Comum \& Inf, v. 16, n. 2, p. 05-22, jul./dez. 2013 
sistematização do dicionário, dando-lhe maior formalidade e auxiliando o usuário na busca de informações.

Por fim há uma terceira corrente iniciada por Hausemann e Wiegand (1989) e continuadas por Werner (1997) e outros, que fala de cinco pontos de vista para descrever o dicionário: a hiperestrutura (parte pré-textual, guias de usos e apêndices); a macroestrutura (entradas); microestrutura (definições); iconoestrutura (imagens e ilustrações que acompanham as definições) e as estruturas de acesso (índices) (ISQUIERDO; ALVES, 2007).

Associados à estrutura organizacional comentada acima, há alguns princípios que norteiam a caracterização de um dicionário, são eles: a ordenação (semasiológica ou onomasiológica); o número de línguas (monolíngue, bilíngue ou plurilíngue); a perspectiva temporal (visão sincrônica ou diacrônica); o tipo de compilação do material registrado (caráter exaustivo ou representativo); a extensão (conciso, manual, de bolso) e o suporte (papel ou eletrônico). Além desses principais elementos, existem ainda os aspectos relacionados diretamente aos usuários, como a questão da natureza pedagógica, relativo a determina faixa etária e nível de escolaridade do público-alvo, ou mesmo a densidade da microestrutura, também voltada a uma demanda concreta de usuários (CAMPOS SOUTO; PEREZ PASCUAL, 2003).

No âmbito deste trabalho, além dos princípios mencionados acima foram incorporados para análise os aspectos apresentados por Castillo Carballo (2003) para a macroestrutura e por Medina Guerra (2003) para a microestrutura. Na macroestrutura foram observados os critérios de seleção das entradas (frequência de uso, categoria gramatical, aspectos morfossintáticos) característicos da corrente de Rey-Debove (1971). Mas também foram observados os aspectos prétextuais da introdução, como sugere Günther Haensch (1982 apud MEDINA GUERRA, 2003), que incorpora a funcionalidade e os objetivos do dicionário. E na microestrutura focalizou-se a natureza das acepções (ordem de aparecimento, etimologia, relações semânticas, marcas e exemplos) e a tipologia das definições, quanto à natureza da metalinguagem (próprias ou impróprias) ou quanto à natureza do definido (enciclopédico, explicativo, ostensivo).

Por fim, vale ressaltar o papel da definição, especialmente nas áreas de especialidade, uma vez que permite a observação e a percepção de quanto e como um conhecimento está sendo mobilizado dentro de um domínio (KRIEGER; FINATTO, 2004). Segundo Sager (1993), uma definição adequada deveria ser elaborada a partir do gênero próximo e da diferença específica

Comum \& Inf, v. 16, n. 2, p. 05-22, jul./dez. 2013 
(GPDE). O gênero próximo (GP) ou termo-pai, seria aquele de caráter mais genérico, que pode englobar elementos mais específicos e subordinados a ele conceitualmente. A diferença específica (DE) seria o aspecto particular, que diferenciaria um conceito de outro, dando-lhe um caráter distintivo.

Além dessa estrutura básica para a definição, há também outras possibilidades de elaboração, tais como: a definição a partir de uma análise ou síntese; a utilização de sinônimos; o uso de paráfrases; a definição mediante implicação ou denotação; a enumeração; a definição ostensiva e aquelas que agregam mais de uma tipologia, as mistas.

\section{Análise lexicográfica dos dicionários}

2.1 Dicionário de Comunicação - Rabaça e Barbosa (1978, 1987, 2001)

O Dicionário de Comunicação escrito por Rabaça e Barbosa é um dos materiais lexicográficos mais antigos da área de Comunicação, tendo sua primeira edição em 1978 pela Codecri. Além disso, é obra de maior difusão no gênero, contando com mais de 60 mil exemplares vendidos em seis reimpressões.

Já em sua primeira edição em 1978 possuía cerca de 4000 verbetes, que abarcavam 21 subáreas relacionadas aos estudos comunicacionais, do Jornalismo às subáreas que surgiam naquele momento, a exemplo da Cibernética. Sobre tal subárea é interessante destacar que todos os termos relacionados a tal temática eram agrupados no verbete Cibernética, mesmo aqueles mais técnicos. $\mathrm{E}$ essa subárea, ainda pequena nessa época, expandiu-se no decorrer das edições posteriores, chegando a mais de dois mil verbetes relacionados a ela, agora denominada como Informática.

A proliferação de áreas de pesquisa e a influência tecnológica, principalmente da Informática nesta época, foram ressaltadas pelos autores na introdução, que destacaram a importância de tais modificações para a comunicação de massa. Por outro lado, os autores salientaram que mesmo com a diversidade de subáreas e as modificações tecnológicas, que se intensificaram com o passar do tempo, há elementos comuns que convergem as diferentes esferas das subáreas para a constituição identitária da área da Comunicação.

A parte pré-textual, tanto na primeira edição como nas posteriores, possui um breve panorama das principais temáticas abordadas no dicionário, bem como apresenta as informações organizacionais para facilitar a manipulação do dicionário. Os principais recursos utilizados são as remissões, para sinônimos ou relações de gênero e espécie, e indicações gráficas, como letras 
capitulares, siglas, e até imagens ilustrativas para alguns processos, instrumentos ou fluxos informacionais.

Na edição de 1987, pela editora Ática, os autores ratificam o "espírito do dicionário", uma mescla de verbetes de caráter essencialmente técnico, com definições conceituais e processuais mais elaboradas. $\mathrm{O}$ diferencial em relação a edição anterior está principalmente no aumento da cobertura, chegando próximo a 7000 verbetes, e as inevitáveis mudanças em alguns verbetes, principalmente ligados às novas tecnologias da área, que alteraram o uso ou a concepção de alguns dos verbetes.

A edição da Campus em 2001 seguiu esse padrão de abrangência, ampliando verbetes, atualizando e revisando outros que caíram em desuso na área, principalmente motivados pelas mudanças tecnológicas. Outro aspecto importante de ser ressaltado nessas atualizações foi o enriquecimento quanto à parte da microestrutura, ou seja, na constituição do verbete. Isso ocorreu tanto no nível definicional, ampliando e melhorando a elaboração dos verbetes, a exemplo da recorrência de mais de uma acepção para cada termo, como também ampliando as estruturas de acesso, ratificadas pelo caráter pedagógico da obra.

Escrito por dois professores e pesquisadores da área de Comunicação, sendo um deles, Barbosa, também responsável pela organização dos verbetes de Comunicação do Dicionário Houaiss, o dicionário revela em sua estrutura uma preocupação didática. Tal preocupação pode ser observada tanto na apresentação das acepções (uso de siglas das subáreas para facilitar o entendimento do termo dentro de uma temática, apresentação de variações ortográficas e terminológicas, remissões quanto a sinônimos e relações de gênero e espécie) como no uso de recursos visuais para chamar atenção do leitor (destaque de trechos em negrito e uso de imagens ilustrativas).

Na edição mais recente, de 2001 pela editora Campus, além dos aspectos mencionados há a incorporação de vários verbetes que não são especificadamente da área de Comunicação, mas que são usados por ela, ou que estão em áreas de interface. Nesses casos os autores utilizam o recurso da nota de aplicação, explicando o uso do termo para a área, a exemplo do termo blog. Esse mesmo termo revela uma nova escolha dos autores, que até então evitavam colocar termos estrangeiros, preferindo as traduções ou aportuguesamentos. Nesta última edição há um número maior de empréstimos, o que também revela também o aumento da influência externa na área. A opção de

Comum \& Inf, v. 16, n. 2, p. 05-22, jul./dez. 2013 
apresentação desses empréstimos aparece primeiro com a forma aportuguesada ou decalque, seguida da expressão no idioma de origem e depois a acepção.

Como qualquer outra obra lexicográfica reflete a perspectiva ideológica de seus criadores, assim, mesmo que alguns conceitos não sejam apresentados de forma mais detalhada ou com o viés de determinada linha de estudo, este dicionário destaca-se como uma obra de referência da área. Primeiro por manter-se ativo e atualizado por tanto tempo. Segundo por suplantar o caráter mais recorrente na área, de mero glossário, ou seja, trazer elementos que o ratificam como um dicionário: a cobertura, abrangência, tratamento temático, estrutura organizacional e conceitual. Terceiro por ser um material lexicográfico de conteúdo diversificado que atende diferentes públicos, tanto aos pesquisadores acadêmicos, com acepções mais conceituais, como os profissionais da área, apresentando os jargões e termos técnicos.

É interessante ressaltar também a preocupação dos autores em incorporar situações de uso dos verbetes, não apenas contentando-se em expressar sua acepção. Um exemplo evidente pode ser visto na preocupação em diferenciar os usos de um mesmo termo no português do Brasil e no português de Portugal, a exemplo do termo furo jornalístico no Brasil e cacha em Portugal. Outra tendência dos autores é incorporar ao dicionário verbetes voltados à formação humanística do profissional, a exemplo de termos como responsabilidade social ou empresa cidadã, que revelam a importância de se agregar à formação a perspectiva humanística.

O que poderia ser melhorado na macroestrutura do verbete seria a indicação das fontes bibliográficas. A indicação da referência utilizada pelos autores poderia orientar melhor a compreensão sobre o conceito e a linha de pesquisa adotada, justificando assim as escolhas terminológicas, uma vez que podem ocorrer divergências quanto às acepções, principalmente em termos em que não há um consenso explícito entre os especialistas, a exemplo do próprio termo comunicação.

\subsection{Dicionário de Comunicação - Marcondes (2009)}

O Dicionário de Comunicação organizado pelo professor Ciro Marcondes Filho e publicado pela Editora Paulus é fruto do trabalho de cerca de sessenta profissionais da área de Comunicação. Os autores elaboraram um dicionário bem organizado e com informações sistemáticas, além de terem a preocupação de salientar a identidade da área. Já na introdução o organizador traz à tona o

Comum \& Inf, v. 16, n. 2, p. 05-22, jul./dez. 2013 
problema da visão que minimiza o valor da área, colocando-a como mera "área de aplicação de outros campos". Em contraponto a tal perspectiva, o organizador destaca o objetivo da obra, ratificar a função reguladora e ordenadora da área da Comunicação, buscando rever os conceitos, aperfeiçoá-los e enxergá-los no escopo da área (MARCONDES, 2009).

$\mathrm{Na}$ parte pré-textual, além de apresentarem explicitamente o objetivo da obra, os autores oferecem um breve panorama sobre a área da Comunicação, abordando principais temáticas, abordagens, e um sucinto histórico. Em seguida, justificam sua relevância como obra de referência na área, comprovada pela escassez de materiais sistemáticos e referenciais nesse domínio, além de oferecer orientações de uso e acepções elaboradas por profissionais de renome da área.

Quanto à parte organizacional, na introdução também explicam as escolhas terminológicas, bem como o uso de marcas e remissivas. Há ainda uma preocupação com a uniformidade léxica, principalmente evidenciada pelo termo media, usado como termo preferencial ao invés de mídia, vicio acadêmico brasileiro que trata de modo inequívoco processos comunicacionais (cinema, jornal, TV, rádio, etc.).

O dicionário apresenta os verbetes organizados semasiologicamente e alfabeticamente, tendo basicamente dois tipos de verbetes: conceitos e pensadores da área. Em relação às marcas de uso, o principal recurso é a marcação se o verbete é um conceito ou corresponde a dados biográficos ou correntes de pensamento, no caso de pensadores. Além disso, há o uso de dois tipos de remissivas: "temas próximos", para relações hiperonímias e hiponímias, e "temas correlatos", para relações associativas.

A macroestrutura do verbete é bem sistemática e padronizada. $\mathrm{O}$ verbete contém as seguintes partes: termo, etimologia, definição e suas devidas acepções em outras áreas, remissivas (temas próximos e/ou correlatos) e a autoria do verbete. No caso dos verbetes biográficos são apresentados sinteticamente os dados da vida do pensador, suas contribuições para a área, as principais obras e as remissivas.

Nas acepções é interessante observar a preocupação dos autores em salientar a noção do verbete e não apenas seu conceito, ou seja, não se limitam a apresentar traços conceituais fechados ou apenas voltados a aspectos técnicos. As acepções são mais abertas e geralmente trazem as interfaces com outras subáreas e áreas de conhecimento, evidenciando a extensão da área.

Comum \& Inf, v. 16, n. 2, p. 05-22, jul./dez. 2013 
O que poderia ser melhorado na macroestrutura do verbete seria a indicação das fontes bibliográficas. Mesmo tendo o diferencial de apontar o autor do verbete, algo que em muitos dicionários passa indiferente, seria interessante ter indicações sobre a referência utilizada pelos autores para a composição de cada verbete, o que poderia orientar melhor a compreensão sobre o conceito e a linha de pesquisa adotada.

Outro ponto que poderia ser revisto é em relação à etimologia. Claramente as origens etimológicas foram retiradas de um dicionário de língua, mas não há uma menção de que dicionário foi utilizado, nem seu critério de seleção. A indicação da referência, principalmente no âmbito de um dicionário de especialidade é importante por desvelar e justificar as escolhas epistemológicas e até ideológicas dos autores.

Quanto aos recursos multimodais e visuais há praticamente a ausência de sua utilização. As marcações visuais se restringem ao negrito, itálico e letra capitular. Poderia ser explorado o recurso de imagens ou mesmo destaques no texto para ajudar na localização de informações no verbete, uma vez que as acepções são bem extensas.

Por fim, no que tange à microestrutura, observa-se a elaboração bem detalhada, organizada e sistemática. De forma geral é uma definição descritiva ou aristotélica para os conceitos, e enciclopédica para as personalidades. Há uma constante preocupação em se fazer uma breve contextualização histórico-social do termo, tanto o conceito quanto à personalidade. No caso de conceitos, também apresenta alguns exemplos de aplicações, o que facilita para o leitor o entendimento do termo no contexto de uso na área.

Na parte pós-textual há uma lista dos autores da obra, com uma breve nota biográfica sobre sua atuação na área e e-mail de contato. Contudo, como foi observado anteriormente, faltaram as fontes referenciais utilizadas pelos autores. O que enriqueceria mais ainda a consulta ao dicionário.

\subsection{Dicionário de Termos de Marketing}

O Dicionário de termos de marketing: definições, conceitos, palavras-chave de marketing, propaganda, pesquisa, comercialização, comunicação e outras áreas correlatas (2003), de Moreira, Pasquale e Dubner publicado pela editora Astal, já está em sua quarta edição, e tornou-se uma obra de referência para a subárea de Propaganda e Marketing. Elaborado por profissionais da área, teve na época da publicação da última edição mais de 10.000 exemplares vendidos.

Comum \& Inf, v. 16, n. 2, p. 05-22, jul./dez. 2013 
Na primeira edição, em 1996, os autores salientavam a importância de uma obra lexicográfica para a subárea, que até então não tinha tal publicação no Brasil. Já na segunda edição, dois anos depois, além dos termos já consagrados, os autores incorporaram outros termos de subáreas afins, também utilizados no domínio da Propaganda e Marketing. Na terceira edição, ampliaram o dicionário com verbetes em inglês e contaram com o auxílio de novos colaboradores, o que enriqueceu a diversidade de verbetes e a melhor construção das acepções. Por fim, nessa última edição, além de mais termos em inglês, também foram incorporadas siglas e aumentaram o número de novos colaboradores.

$\mathrm{Na}$ parte pré-textual do dicionário encontramos apenas uma nota de agradecimento aos colaboradores, as cópias das apresentações das edições anteriores, e uma breve apresentação dessa edição. Os principais destaques são a quantidade de exemplares vendidos e o fato da nova edição contar com novos colaboradores. Todavia, ao contrário do esperado, não há nenhuma menção sobre a organização do dicionário, nem explicação sobre a elaboração dos verbetes, ficando subentendido, pela presença da bibliografia no final, que foi dali que retiraram as acepções. Contudo, não há um esclarecimento se as acepções foram simplesmente copiadas das obras de referência ou parafraseadas. Além disso, também não há uma indicação explícita de quem elaborou determinada definição.

Quanto à macroestrutura, opta-se pela consagrada organização lexicográfica, a semasiológica e alfabética. No entanto, os verbetes se constituem tanto de lexias simples, podendo ser nominais ou verbais, como lexias complexas, principalmente para indicar expressões e jargões da área de especialidade. Além disso, também são incorporadas como verbetes as siglas em português, tendo espaço no final apenas uma lista das siglas em inglês, sem menção a sua correspondência em português.

Quanto à microestrutura, percebemos que as acepções são bem sintéticas, podendo ser de caráter enumerativo, descritivo e funcional. Não há informações etimológicas ou enciclopédicas. Os verbetes são bem curtos, tendo em média duas linhas. Além da própria acepção, há apenas o uso de remissivas para os casos de sinônimos e termos associados. Hiperônimos, hipônimos e termos associados indicados, em alguns casos não possuem uma definição correspondente que possa explicar ou ampliar a definição pesquisada, apenas remete-se a um sinônimo.

Comum \& Inf, v. 16, n. 2, p. 05-22, jul./dez. 2013 
Além disso, a elaboração da redação das definições também é um problema, tanto por não ter um padrão sistematizado para a construção da acepção, como pelo fato de ter construções circulares, que causam confusão na compreensão do sentido dos termos. E como muitos dicionários, também apresenta o problema das pistas falsas no uso das remissivas ou mesmo o uso de sinônimos, que não traz uma correspondência exata entre termo e conceito. Tais situações limitam o nível de profundidade do dicionário, restringindo-o a um uso mais pontual e pouco especializado.

As remissivas são indicadas simplesmente com o termo veja. Todavia, nesta categoria são reunidos diferentes tipos de relações entre os verbetes. Há relações hiperonímicas, hiponímicas, sinonímicas, associativas e também de gênero/ espécie, contudo não há qualquer marcação dessa distinção relacional, o que pode também dificultar a compreensão dos verbetes.

Outro detalhe a ser mencionado é a questão do nível de formalidade escolhido. Se por um lado é interessante a incorporação dos jargões da área, a exemplo de "abacaxi” (negócio muito lento), tal escolha sem a devida marcação de uso pode ser confundida com os termos mais técnicos, e para um profissional em formação podem gerar problemas quanto ao nível de formalidade da escolha lexical.

Outro aspecto que poderia enriquecer a consulta ao dicionário seria o uso de recursos multimodais, imagens, cores, enquadres, saliências, ou seja, recursos visuais que poderiam auxiliar na identificação de informações específicas dos verbetes.

Por fim, constatamos que apesar de alguns problemas quanto à padronização da macro e microestrutura o dicionário destaca-se pela sua abrangência e cobertura. Além disso atende a uma demanda crescente de profissionais da subárea da Propaganda e Marketing, sendo um dos materiais lexicográficos mais especializado e atualizado para este domínio.

2.4 Dicionário de Mensuração e Pesquisa em Relações Públicas e Comunicação Organizacional Stacks (2008)

O Dicionário de Mensuração e Pesquisa em Relações Públicas e Comunicação Organizacional elaborado pelo Ph.D Don W. Stacks, da Universidade de Miami, é desde sua publicação nos Estados Unidos um material de referência para profissionais e acadêmicos desta subárea. Em português foi organizado por Paulo Nassar e Suzel Figueiredo, traduzido por Ciro Coutinho e editado pela Aberje - Associação Brasileira de Comunicação Empresarial, sociedade

Comum \& Inf, v. 16, n. 2, p. 05-22, jul./dez. 2013 
civil sem fins lucrativos, voltada a discutir e promover a Comunicação Empresarial e Organizacional nas perspectivas administrativa, política e cultural (ALBERJE, 2012).

A obra é resultado da iniciativa do autor junto à Comissão de Mensuração e Avaliação em Relações Públicas, do Institute for Public Relations nos EUA, em estabelecer métodos para mensuração da pesquisa em Relações Públicas, bem como tentar alinhar e democratizar o discurso deste domínio tanto no meio profissional como acadêmico, devido principalmente a problemática das divergências terminológicas. Tais objetivos são expostos já na introdução do dicionário, que conta também com a nota da primeira edição, de 2002 (ALBERJE, 2012).

Ao contrário da primeira edição, a de 2008 traz não apenas mais verbetes, mas também maior elaboração das remissivas e das acepções, contando com uma maior equipe de profissionais colaboradores e com a internet. $\mathrm{O}$ fato de parte do trabalho do dicionário ter sido divulgado no site do Institute for Public Relations fez com que o público leitor pudesse participar ativamente com sugestões, dúvidas e colaborações na feitura das acepções. Mesmo agora com o dicionário pronto e impresso, o autor salienta que ele não está terminado, convidando assim os novos leitores para participarem da discussão da obra e de sua dinâmica de elaboração.

Na parte pré-textual, há ainda uma preocupação de se enunciar como a obra está organizada. Os verbetes estão classificados segundo duas tipologias, estatísticos e metodológicos, trazendo a categoria abreviada logo após o nome do verbete. Em seguida é enunciada a acepção, definida segundo as instâncias profissionais, geralmente de caráter sintético e objetivo, seguindo padrão definitório de gênero/ espécie. Por fim, o verbete ainda pode apresentar seu sinônimo em inglês, escolha dos tradutores em deixar os termos estrangeiros de uso recorrente na área.

Quanto à microestrutura, percebemos que as acepções são bem sintéticas, podendo ser de caráter enumerativo, descritivo e funcional. A opção pela acepção curta e objetiva é compreensível considerando-se o público-alvo e a suposta utilização mais pontual da obra. Contudo, seria interessante, mesmo utilizando o recurso de siglas ou abreviações, haver uma menção mais direta às fontes utilizadas para elaboração das acepções. Outro aspecto importante é a questão problemática da tipologia dicotômica escolhida, termos estatísticos e metodológicos, uma vez que há casos em que os conceitos são híbridos, e não há uma menção explícita na obra sobre os critérios objetivos usados para determinar tal classificação. Um exemplo ilustrativo seria o termo análise demográfica colocado como metodológico, mas que em essência é termo de natureza estatística.

Comum \& Inf, v. 16, n. 2, p. 05-22, jul./dez. 2013 
Quanto aos recursos visuais utilizados destacam-se: a letra capitular, no início de cada letra do alfabeto, e a marca d'água, no início de cada seção com a lista dos verbetes colocados sucessivamente. Este último recurso é até interessante visualmente, mas não ajuda o leitor efetivamente a identificar a lista de termos de cada seção, para isso seria necessário a elaboração de um sumário no início da obra, ou de um índice que pudessem facilitar a identificação pontual de termos.

O uso das remissivas também é praticamente inexistente, recurso que se fosse mais explorado seria muito válido ao relacionar termos com nítidas relações de hiperonímicas, hiponímicas, associativas e sinonímicas, a exemplo do termo genérico análise, e suas diversas facetas hiperonímicas: análise bivariacional, análise demográfica, análise de erro, etc.

Por fim, mesmo com as carências apontadas acima, a obra destaca-se por sua organização e sistematização dentro da proposta apresentada, público-alvo e do uso sugerido pelos autores.

\section{Considerações finais}

Os dois primeiros dicionários analisados destacam-se como obras de referência na área, tanto pela abrangência temática como pelo tratamento dado aos verbetes, do aspecto estrutural ao semântico. O dicionário de Rabaça e Barbosa confirma em suas diferentes edições e no zelo dos autores pela elaboração e atualização dos verbetes, seu papel de obra clássica na área da Comunicação. Por outro lado, o dicionário organizado por Marcondes, mesmo de caráter recente, ratifica-se como obra de referência pela apurada organização e tratamento conceitual dado aos verbetes, que dentre os dicionários analisados é o mais elaborado.

Os dicionários de Marketing e de Relações Públicas, também pela natureza mais especializada, não possuem uma grande cobertura temática, em comparação com os dois primeiros, restringindo-se aos aspectos de seu subdomínio. Diferentemente dos Dicionários de Comunicação, de caráter mais abrangente, esses dois estão voltados a públicos mais especializados e técnicos, o que lhes confere nuanças próprias.

As acepções são mais sintéticas e o uso de jargões é mais recorrente, fatores que contribuem para sua caracterização como obras de determinados subdomínios. Por outro lado, como obras lexicográficas seria coerente utilizarem recursos lexicográficos que melhor adequassem seu 
conteúdo à tipologia documental. Para isso deveriam utilizar melhor a organização, sistematização e estruturação das informações, facilitando a utilização de seu público-alvo.

A questão do público-alvo e dos objetivos dos dicionários é fundamental para a decisão de que tipo de obra lexicográfica será feita. Nesse caso observamos que os dicionários analisados ilustram objetivos e públicos distintos. O dicionário de Rabaça e Barbosa poderia ser considerado o mais genérico, uma vez que abarca diferentes subdomínios da Comunicação, agregando tanto aspectos mais técnicos como teóricos em suas acepções, servindo portanto, ao profissional e ao pesquisador . Já no dicionário de Marcondes observa-se um viés mais teórico e reflexivo, voltado principalmente para o pesquisador, não só da área de Comunicação como das áreas de interface. Os outros dois dicionários, de Marketing e Relações Públicas, pelo seu teor e constituição, indicam um uso mais técnico, voltado às necessidades do profissional das subáreas.

Tendo em mente os aspectos positivos e negativos aqui apresentados pelos dicionários da área de Comunicação, propomos como síntese desse trabalho um roteiro de orientação para a elaboração de dicionários nesse domínio. O roteiro foi elaborado segundo a metodologia de elaboração de obras lexicográficas de Medina Guerra (2003), Campos Souto e Perez Pascual (2003) e Castillo Carballo (2003), subdividida em quatro partes: hiperestrutura (parte pré-textual e introdução), macroestrutura (entradas dos verbetes), microestrutura (definições dos termos) e a parte pós-textual (estruturas de acesso e índices). Abaixo um quadro sinóptico do roteiro (Quadro $1)$ :

Quadro 1- Roteiro de elaboração de dicionários

\begin{tabular}{|l|l|}
\hline Etapa de análise & Elementos de análise \\
\hline 1 Parte pré-textual & Introdução: \\
& Abordar um breve panorama da área; \\
& Informações sobre a equipe e dados sobre a \\
elaboração do dicionário;
\end{tabular}

Comum \& Inf, v. 16, n. 2, p. 05-22, jul./dez. 2013 


\begin{tabular}{|c|c|}
\hline 3 Análise da Microestrutura & $\begin{array}{l}\text { 3.1 Cabeça do verbete: escolher critérios de } \\
\text { padronização (uso de variantes ortográficas, } \\
\text { etimologia, sinônimos em outro idioma, etc.) } \\
\text { 3.2 Escolha do tipo de acepção: } \\
\text { a) Aristotélica (das palavras para as coisas, foco } \\
\text { funcional); } \\
\text { b) Lexicográfica (proposição de equivalência } \\
\text { entre o termo, o definido e o conjunto que o } \\
\text { caracteriza); } \\
\text { c) Enciclopédica (resumo de conhecimentos); } \\
\text { d) Descritiva (apontamento dos principais traços } \\
\text { característicos); } \\
\text { e) Extensional (enumerativa); } \\
\text { f) Sinonímica; } \\
\text { g) Antonímia; } \\
\text { h) Paráfrase de outra definição; } \\
\text { 3.3 Uso de elementos auxiliares: exemplos; } \\
\text { informações gramaticais; marcas de uso } \\
\text { (diatécnicas, diatópicas e diacrônicas); uso de } \\
\text { remissivas (sinonímicas ou associativas), uso de } \\
\text { recursos multimodais para destacar as } \\
\text { informações (imagens, saliências, cores, etc.). }\end{array}$ \\
\hline 4 Parte Pós-textual (opcional) & $\begin{array}{l}\text { 4.1 Lista de verbetes correspondentes em outro } \\
\text { idioma. } \\
\text { 4.2 Referências completas } \\
\text { 4.3 Lista dos autores, com notas biográficas e de } \\
\text { sua respectiva área de atuação e contato. }\end{array}$ \\
\hline
\end{tabular}

Fonte: Elaboração própria.

Artigo submetido em 21/10/2013 e aceito em 24/02/2014.

\section{Referências}

AHUMADA LARA, I. Aspectos de lexicografia teórica. Granada: Estudios de Lengua Española, 1989.

ASSOCIAÇÃO BRASILEIRA DE COMUNICAÇÃO EMPRESARIAL. Associação. São Paulo: Alberje, 2012. Disponível em: 〈http://www.aberje.com.br/associacaoquemsomos.asp >. Acesso em: 24 fev. 2014.

BIDERMAN, M. T. C. A ciência da lexicografia. Alfa, São Paulo, n. 28, p. 1-26, 1984.

BIDERMAN, M. T. C. Teoria linguística: teoria lexical e linguística computacional. 2. ed. São Paulo: Martins Fontes, 2001.

CARBALLO, M. A. C. La macroestructura del diccionário. In: GUERRA, M. A. M. Lexicografia espanhola. Barcelona: Editorial Ariel, 2003.

Comum \& Inf, v. 16, n. 2, p. 05-22, jul./dez. 2013 
COORDENAÇÃO DE APERFEIÇOAMENTO DE PESSOAL DE NÍVEL SUPERIOR. Tabela de áreas de Conhecimento. Brasília: MEC, 2008. Disponível em:

<http://www.capes.gov.br/avaliacao/tabela-de-areas-de-conhecimento>. Acesso em: 24 fev. 2014.

GUERRA, M. A. M. Lexicografia espanhola. Barcelona: Editorial Ariel, 2003.

ISQUIERDO, A. N.; ALVES, I. M. (Orgs.). As ciências do léxico: lexicologia, lexicografia, terminologia. Campo Grande: Humanitas, 2007.

KATZ, C. S.; DORIA, F. A.; LIMA, L. C. Dicionário básico de comunicação. 2. ed. rev. e atual. Rio de Janeiro: Paz e Terra, 1975.

KLEIN, J. T. Interdisciplinarity and complexity: an evolving relationship. E-CO, v. 6, n. 1-2, 2004.

KRIEGER, M. G.; FINATTO, M. J. B. Introdução à terminologia: teoria e prática. São Paulo: Contexto, 2004.

MARCONDES FILHO, C. Dicionário de comunicação. São Paulo: Paulus, 2009.

MOREIRA, J. C. T.; PASQUALE, P. P.; DUBNER, A. G. Dicionário de termos de marketing: definições, conceitos e palavras-chave de marketing, propaganda, pesquisa, comercialização, comunicação e outra áreas correlatas. 4. ed. São Paulo: Astal, 2003.

RABAÇA, C. A.; BARBOSA, G. G. Dicionário de comunicação. Rio de Janeiro: Codecri, 1978.

RABAÇA, C. A.; BARBOSA, G. G. Dicionário de comunicação. São Paulo: Ática, 1987.

RABAÇA, C. A.; BARBOSA, G. G. Dicionário de comunicação. Rio de Janeiro: Campus, 2001.

REY-DEBOVE, J. Étude linguistique et sémiotique des dictionnaires français contemporains. Mouton: The Hague-Paris, 1971.

SAGER, J. C. Curso práctico sobre el procesamiento de la terminología. Madrid: Fundación G. S. Ruipérez, 1993.

SOUTO, M. C.; PASCUAL, J. I. P. El diccionário y otros productos lexicográficos. In: GUERRA, M. A. M. Lexicografia espanhola. Barcelona: Editorial Ariel, 2003.

STACKS, D.W. Dicionário de mensuração e pesquisa em Relações Públicas e comunicação organizacional. São Paulo: ALBERJE, 2008.

Comum \& Inf, v. 16, n. 2, p. 05-22, jul./dez. 2013 